\title{
Auditory Pathway of the Epileptic Waltzing Mouse \\ I. A COMPARISON OF THE ACOUSTIC PATHWAYS OF THE NORMAL MOUSE WITH THOSE OF THE TOTALLY DEAF EPILEPTIC WALTZER
}

\author{
MURIEL D. ROSS \\ Department of Anatomy, Medical Center, University of Michigan, \\ Ann Arbor, Michigan
}

Waltzing and epilepsy are hereditary traits which appear independently or together in various stocks of mice of the genus Peromyscus. They are inherited in general as Mendelian recessives (Dice, '35; Watson, '39). Young members of the particular stock of Peromyscus maniculatus artemisiae to be described in this study exhibit both waltzing and epilepsy when stimulated by sounds of various kinds. At the sound of jingling keys, or of certain pure tones, the young epileptic waltzer whirls in circles and then dashes wildly about the enclosure. After a few seconds, he falls upon his side in an epileptic seizure. His body becomes rigid, his forelegs are flexed and his hind legs are extended. The animal resumes his circus movements after recovering from the seizure but whirls in a graceful manner, not wildly as before. As the mouse grows older, it is more and more difficult to induce the waltzing and epileptic attack. Finally, the animal appears to become deaf, for he gives no visible sign that he hears the sound stimulus. His ears do not twitch and he shows no uneasiness.

This study represents an attempt to assess possible nervous system changes related to the loss of hearing exhibited by these mice. In Part I of this report, the central relations of the auditory systems in older, deaf epileptic waltzers will be compared with those in normal controls of the genus Peromyscus. The auditory centers of young, partially deaf, epileptic waltzing mice will be considered separately in Part II.

The author is deeply indebted to Dr. Elizabeth C. Crosby for her helpful criti- cisms of this paper, and to Dr. Edward Lauer for his suggestions and his assistance in matters of technique. She is also grateful to Dr. Lee R. Dice and the Laboratory of Vertebrate Biology for making the mice and the testing equipment available to her for this study, and to Dr. Elizabeth Barto, who tested the mice for range of hearing. Assistance was obtained from a grant from the Alfonso Morton Clover Scholarship and Research Fund to the Laboratory of Comparative Neurology for the preparation of the material for microscopic examination. Aid in testing the responses of the experimental animals used in this study was supplied through a grant (MH 375) to Dr. Lee R. Dice from the National Institute of Mental Health, of the National Institutes of Health, Public Health Service.

\section{MATERIALS AND METHODS}

A total of 26 animals was obtained from the Laboratory of Vertebrate Biology for use in this study. Of this number eight animals were normal controls taken from a stock of Peromyscus maniculatus blandus from Tularosa, New Mexico. They showed neither waltzing nor convulsive behavior when exposed to the stimulus of jingling keys for 90 seconds. The rest of the animals were epileptic waltzers, hybrids between several subspecies of mice. Nine of the epileptic waltzers were considered deaf because they did not twitch their ears in response to a tap on glass, to a squeak, or to keys jingling, and the last procedure did not cause waltzing or a seizure. Six animals were young, possessed acute hearing, and both waltzed and had a convulsive 
seizure when exposed to the sound of the jingling keys. Three animals had less acute hearing than the young mice; they suffered less violent reactions to key jingling, as evidenced by a weak dash or ear twitching. One deaf and one young mouse died of natural causes, leaving 24 animals which were actually prepared for study.

At the end of the experimental testing, all of the animals were sacrificed and perfused. Seventeen of these animals were perfused with $10 \%$ formalin; seven with a special modification of the Zenker-formol solution described by Guild ('19). Then, the skull cap was opened and the lower jaw and muscles of the head were cut off. The brains were allowed to harden in situ in $10 \%$ formalin for several days and then the temporal bones and/or the brains were removed.

Nome of the cochleae were suitable for study and will not be considered further here. Of the 16 brains which were removed, three were fixed, cleared, and embedded according to the Huber-Guild pyridine-silver method. The tissue became very hard and shattered when cut at a thickness of $20 \mu$. The 13 remaining brains were fixed, cleared, and embedded in paraffin according to the usual methods. Seven paraffin blocks were cut on a rotary microtome in sections $25 \mu$ thick, mounted serially, and stained after the Weil method for fibers. Two brains were cut at $15 \mu$, mounted in serial sections, and stained with cresyl-echt-violet. The remaining four brains were cut at $25 \mu$, mounted serially, and stained with toluidin blue. All of the brains were cut transversely.

The first part of this report is based upon a study of the acoustic pathway in four series of brains. Brain no. 87932 (normal, female) and brain no. 85842 (deaf, female) were stained according to the Weil method. Brain no. 87120 (normal, male) and brain no. 85836 (deaf, male) were stained with cresyl-echt-violet.

\section{DESCRIPTION OF THE NORMAL MATERIAL}

\section{Primary auditory centers}

Dorsal cochlear nucleus. The acoustic tubercle of the mouse (figs. 1, 2, 3) is comparable with the dorsal cochlear nucleus of higher forms. It is located in the medulla oblongata dorsolateral to the restiform body. The posterior end of the tubercle lies at the level of the lateral recesses of the fourth ventricle. As it is followed forward, the dorsal cochlear nucleus increases in size ventrolaterally and, to a lesser degree, in thickness, reaching its greatest development in its middle third. In these sections it lies dorsolateral to the ventral cochlear nucleus and to the restiform body. Rostral to a plane through the caudal part of the genu of VII, the dorsal cochlear nucleus shortens dorsoventrally and gradually flattens into a narrow band of granular cells which still covers the dorsolateral surface of the ventral cochlear nucleus. Both ventral and dorsal cochlear nuclei extend rostrally to a plane through the motor nucleus of the trigeminal nerve.

The internal organization of the acoustic tubercle differs at various levels. Caudally, it is composed of a few delicate fibers and numerous cells; the latter are either small in size, fusiform or round, and darkly staining, or they are of medium-size, spherical and pale staining. No pattern of distribution of the cells or of the fibers is observed at this level. As the acoustic tubercle broadens, the fibers within it become thicker and more numerous and the cells increase in number. A dis. tinct lamination of the tubercle, involving both the cells and the fibers, begins at the level of the facial nucleus and ends rostrally in sections through the genu and roots of VII. The distance between the caudal pole of the acoustic tubercle and the onset of lamination within it is very short.

Among the observers who have described the Iamination of the acoustic tubercle in mammals are Ramón y Cajal ('09), Winkler and Potter ('11, '14), and, more recently, Lorente de Nó ('33). Each of the these workers recognized four fundamental layers, although the laminae described by each include different elements and the nomenclature varies. Lorente de Nó, working with Golgi preparations of mouse and cat brains, subdivided the acoustic tubercle still further. In addition to the four laminae, he found several other distinct areas. In the primary acoustic nuclei as a group, he de- 
fined at least 13 different regions and 40 to 50 types of neurons.

In the acoustic tubercle of the mouse material studied for this paper, four layers are distinguishable lying in a lateromedial direction; these will be described from the surface toward the restiform body. The most superficial lamina, Layer $I$, is poor in fibers and cells (fig. 2). Beneath the pia there are small, round or fusiform, dark staining cells intermingled with others medium in size, round or ovoid, and pale staining. This lamina I corresponds to both the surface ("epithelial") and the "superficial plexiform" layers of Ramón $y$ Cajal, and to the "stratum griseum superficiale" of Winkler and Potter ('11).

Winkler and Potter employed "lamina cellularis" for the second layer, which is rich in cells as the terminology suggests. This lamina is Ramón y Cajal's "zone of granule and large fusiform cells." Layer II (fig. 2) is especially characterized in the mouse by the presence of spindleshaped cells, which generally lie with their long axes at right angles to the surface of the acoustic tubercle. These cells are small or of medium-size in the mouse and vary in their staining quality; mingled with them are many small, dark, round cells.

Within the third layer (fig. 2) polymorphous neurons are arranged between numerous diagonally cut fibers. The fibers are, for the most part, of two derivations: some of them are cochlear nerve fibers on their way to the cells of the dorsal cochlear nucleus where they terminate; others have their origin within the latter nucleus and are the axons of secondary neurons which ascend to higher levels. This layer corresponds to Winkler and Potter's ('14) "stratum medullare superficiale," and to Ramón y Cajal's "deep plexiform layer" or "zone of large nerve cells."

The deepest layer of the acoustic tubercle (fig. 2), the "stratum medullare profundum" of Winkler and Potter, is composed of cochlear nerve fibers, which enter it ventrally, and of the axons of the previously mentioned secondary neurons which are gathering into a heavy bundle medially. This bundle of fibers emerges dorsomedially from Layer IV and then swings dorsalward over the restiform body and toward the midline as dorsal secondary cochlear fibers.

In addition to the lamination just described, some authors have recognized further cell groupings within the acoustic tubercle. Thus, Winkler and Potter have described a nucleus proprius, which represents the central unlaminated core of the tubercle. In mouse brain no. 87120 , stained for cells, nucleus proprius begins in sections at the level of the facial nucleus, just caudal to the beginning of lamination of the acoustic tubercle. Some of its cells can be traced rostrally to sections through the caudal end of the genu of VII. At this level, with an increase of similar cells within the rest of the acoustic tubercle, the nucleus proprius can no longer be distinguished.

Nucleus proprius (figs. 1, 2, 3) varies considerably in size from level to level, but small, round, dark staining cells are present throughout. They were called "grains" by Winkler and Potter ('11, '14), and are closely grouped together. Most caudally these "grains" spread in a thin layer across the ventromedial two thirds of the acoustic tubercle. Initially the cells do not attain the most ventral portion of the dorsal cochlear nucleus, but do come to this area shortly. Nucleus proprius reaches its greatest size, occupying most of the ventral fourth of the acoustic tubercle, in sections in the plane of the caudal pole of the ventral cochlear nucleus. As the cells of the ventral cochlear nucleus increase in number ventralward, they divide nucleus proprius into a lateral and a medial portion. The medial portion is smaller and ends within $60 \mu$. The dorsal portion becomes reduced in size but can be traced to the oral limit of the nucleus. The fiber content within nucleus proprius is never great; delicate fibrils ramify between the closely arranged cells.

Ventral cochlear nucleus. The ventral cochlear nucleus (figs. 2,3 ) does not extend so far caudalward as does the acoustic tubercle. It begins at the level of the facial nucleus and ends rostralward at the level of the motor nucleus of the trigeminal nerve. Ramón y Cajal ('09, '11) and Lorente de Nó ('33) have described various zones in this nucleus, According to Ramón y Cajal it has two parts, an an- 
terior or rostral portion and a posterior or caudal portion. This division is based upon the presence of a "tail" or dorsal extension of the ventral cochlear nucleus which lies internal to the caudal part of the acoustic tubercle. Four zones were described by Ramón y Cajal for the ventral part of the ventral cochlear nucleus, but they were not present in the dorsal extension or in the anterior levels of the nucleus. These zones were named in lateromedial order: (1) an "epithelial layer"; (2) a superficial plexiform zone; (3) a zone of small cells; (4) a zone of large cells and of fiber bundles. This description of the lamination was based upon his preparations of the cat, the rabbit, and the guinea pig. Lorente de Nó ('33) divided the ventral cochlear nucleus of the mouse and cat in the dorsoventral direction into regions I, II and III.

In the mouse brains reported here a division into rostral and caudal portions has been made. The caudal subdivision (fig. 2) begins as a few cells lying ventromedial to the tubercle, but increases rapidly in size to form a rounded hillock. The dorsal slope of the hillock is extended dorsally so that it lies medial to the acoustic tubercle and lateral to the restiform body. This dorsal portion is lengthened in such a fashion in the two mouse brains studied and corresponds to the dorsal extension or "tail" described by Ramón y Cajal. In planes through the caudal part of the genu of VII, the dorsal slope of the ventral cochlear nucleus rounds considerably (fig. 3) and such a "tail" is no longer observed. With the disappearance of the dorsal extension, the caudal subdivision ends and the rostral portion begins. This latter subdivision extends forward to the level of the motor nucleus of the trigeminal; caudally it is rounded in outline (fig. 3 ) but, at the level of the vestibular nerve, the hillock shortens and the lateral surface of the nucleus soon flattens. The entire nucleus diminishes in size very gradually in such a way that, rostrally, it is narrower dorsally than ventrally. Its lateral surface is rather straight and its ventral border slopes gently.

Such a high degree of organization of cells and fibers into a definite pattern as was described for the acoustic tubercle is not evident in the ventral cochlear nucleus of these mice. A layer of flattened pial cells covers the nucleus except in the "tail." Internal to this lamina, a thin layer of dark, closely arranged, granular cells is observed. These cells are directly continuous with the granules observed in nucleus proprius and in the anterior end of the acoustic tubercle; they are not present along the dorsolateral border of the ventral cochlear nucleus caudal to the level of the superior olive. Medial to the layer of the granule cells, and in the so-called "tail" of the nucleus, are the neurons and fibers which make up the bulk of the ventral cochlear nucleus. The most prominent of these neurons are large, triangular or oval in shape, and have large, oval nuclei; their cytoplasm takes on a very characteristic violet color in the cresyl violet material. Smaller, round and fusiform cells are intermingled with the large neurons. Rostrally, as the nucleus becomes flat, the cells located dorsally are chiefly oval in shape and are closely grouped; those found ventrally are mostly triangular or spindle-shaped. These cells in the rostral portion of the ventral cochlear nucleus are, on the whole, smaller, more numerous, and more densely arranged than in the caudal part of this nuclear complex.

The cells in the caudal portion of the ventral cochlear nucleus are divided into several rows by layers of longitudinally running fibers. The layers of fibers approximate each other more and more toward the middle of the nucleus, as the level of the cochlear nerve is approached. Here, the ventral cochlear nucleus is divided into a lateral and a medial zone by the thick bundle of cochlear nerve fibers and a small group of cells is situated dorsomedially between the fascicles. In these lateral and medial zones, the fibers form a network among the cells. The cochlear nerve enters the ventral cochlear nucleus ventromedially at the level of the roots of VII, occupying almost all of the ventral and medial parts of the nucleus. Here, only the dorsolateral area exhibits numerous cells and ramifying fibers. Rostral to this level, the nucleus is again divided by a layer of fibers and lateral and medial zones can be distinguished. Most rostrally, the fibers are evenly distributed in the 
ventral cochlear nucleus and no subdivisions are found.

\section{Secondary auditory centers and connections}

Nuclear complex of the superior olive. The superior olive is a folded gray mass extending between the levels of the facial nucleus caudally and those of the motor trigeminal nucleus rostrally. Its cells are of medium-size and of polygonal or fusiform shape; their long axes generally follow the curves of the nucleus. Internal to the superior olive, and closely associated with it, lies the medial accessory olive. This nucleus is somewhat semilunar in outline, although it is much less definite in contour in the mouse than in some other forms. Its cells are also of medium-size and of fusiform or polygonal shape.

Associated with the superior olive (and with the trapezoid body) are two small nuclear masses, the internal and external parolivary nuclei. They lie between the fibers of the trapezoid body, ventral and ventrolateral to the superior olive, respectively. The cells of these parolivary nuclei are spindle-shaped; they are slightly smaller in the external than in the internal parolivary nucleus. In both cases the cells are smaller than those in the superior olive.

Medial to the superior olive and lateral to the medial lemniscus lies an aggregation of cells called the nucleus of the trapezoid body. Its ovoid or polygonal cells are more closely arranged and smaller than those in the medial accessory olive.

Nucleus of the lateral leminiscus. Two nuclear masses are intercalated in the course of the lateral lemniscus, the superior and inferior nuclei of this lemniscus (fig. 7). The inferior nucleus extends rostralward from upper pontine levels to the plane of the caudal end of the inferior colliculus. Caudally, it lies internal to the brachium pontis and rostrally, it is continuous with the more ventral portion of the superior nucleus of the lateral lemniscus. The cells of this inferior nucleus are large, polygonal, and closely arranged.

In sections through the inferior colliculus, there is a loosely organized and elongated cellular aggregation, the superior nucleus of the lateral lemniscus. This nucleus is dorsolateral to the inferior nu- cleus of the lateral lemniscus, to which it is joined caudally by a few strands of cells. The main mass of the nucleus lies in a dorsolateral position ventral to the inferior colliculus. Its cells are large and fusiform or ovoid in shape; many of them lie with their long axes in a horizontal plane.

Within these inferior and superior nuclei are numerous fibrils and heavy bundles of fibers connect the inferior nucleus and the dorsal part of the superior nucleus. The fibers separate the ventral cells of the latter nucleus into strand-like formations; these strands caudally provide a continuity between the two nuclei of the lateral lemniscus. These heavy fascicles may be regarded as internuclear components of the lateral lemniscus.

Inferior colliculus. In the mouse, as in other mammals, the inferior colliculus consists of two portions - a central nuclear mass and a peripheral capsular part (fig. 7). The cells of the central nucleus are rather large and polygonal in shape. At its periphery lies the capsular area consisting of fibers intermingled with rows of cells. Among the fibers are scattered small or medium-sized cells which are fusiform or polygonal in shape.

The fibers of the lateral lemniscus ascending to the inferior colliculus enter the central nuclear mass through the capsule (fig. 7). Most of the axons of the large cells of the central nucleus collect ventrolaterally to the central nucleus within the capsule to enter the peduncle of the inferior colliculus (Held, 1893; Ramón y Cajal, '11; and others). Ramón y Cajal also believed that some of the smaller cells of the capsule send their axons to the medial geniculate nucleus. This peduncle interconnects the inferior colliculus and the medial geniculate nucleus and presumably also carries corticocollicular fibers (Crosby and Henderson, "48).

Medial geniculate nucleus. The medial geniculate nucleus appears caudally as a small, oval shaped mass on each lateral surface of the midbrain at the level of the superior colliculus (fig. 9). In its caudal two thirds it lies posterior to the lateral geniculate nucleus; its rostral portion is medial and slightly ventral to this latter nucleus. The rostral tip of the medial 
geniculate nucleus tapers off into a small group of cells situated in relation to the external medullary lamina ventrally, the ventral nucleus of the thalamus medially, the posterior portion of the lateral nucleus of the thalamus dorsally, and the lateral geniculate body laterally and dorsolaterally. These cells merge with those of the ventral nucleus of the thalamus at levels through the anterior half of the posterior commissure.

Many investigators have described this nucleus in mammals (Ramón y Cajal, '09, in the cat, guinea pig and mouse; Winkler and Potter, '11, '14, in the rabbit and cat; Gurdjian, '27, in the rat; Rioch, '29, in carnivores; Le Gros Clark, '30, '33, in Tarsius and insectivores; and Vogt, '09, Malone, '10, Walker, '37, '38, and many others in primates). Subdivisions have been described by several of these workers, although there is disagreement as to the functional (or even anatomical) significance of such secondary areas.

Several regions are present in the medial geniculate body of the mouse. The two major subdivisions are the pars principalis and the pars magnocellularis, as the areas have been named by Rioch ('29). Pars principalis is the larger and more lateral division and extends the entire caudorostral length of the nucleus. In its middle third it attains its greatest size and has a bean-shape. Pars principalis can be subdivided further into a series of groups of cells or zones, of which the dorsal and ventral are the two major groups.

The dorsal group is characterized by cells which, on the whole, are of mediumsize, although they tend to be somewhat smaller rostrally than caudally. Their cell bodies are triangular or spindle-shaped. These cells stain more darkly and are more loosely arranged than are those of the ventral portion. The dorsal group begins in the posterior fifth of the medial geniculate nucleus as a cap of cells over the ventral portion of pars principalis. In more rostral sections, it assumes a dorsolateral position in relation to the ventral sroup and, along its medial border, cells of different types appear. Some of these cells are large and polygonal; others are small, round or spindle-shaped, and dark staining in material showing Nissl gran- ules. These cells are continued into the dorsal part of the lateral geniculate nucleus and, more rostrally, occupy the position formerly taken by the dorsal portion of pars principalis. In sections through the anterior part of the Edinger-Westphal nucleus, the cells typical of the dorsal group of pars principalis disappear, the last few being located dorsolaterally within the medial geniculate nucleus. On the basis of cell types, rather than position in space, the group of cells appears to be distinct, just as Ramón y Cajal ('09) described it in his mouse specimens. It does not appear to be continuous with the pars posterior of the lateral nucleus of the thalamus as Le Gros Clark ('33) believed.

The ventral group of pars principalis corresponds to Ramón y Cajal's inferior lobe of the medial geniculate nucleus. It extends the entire caudorostral length of this nucleus and may be subdivided into at least three portions; the chief mass, the lateral part, and the ventral part. The chief or central mass of pars principalis consists of cells of medium-size and of oval, triangular, or fuiform shape; they possess large, oval, pale staining nuclei and a cytoplasm which takes a pale violet stain with cresyl violet. In the central mass the cells are arranged in small groups but are generally close to one another. This part, which corresponds to area "a" of Winkler and Patter ('11, '14), and to noyau interne of Ramón y Cajal ('09), extends from the posterior tip to the anterior pole of the nucleus. In sections through the caudal part of the mammillary bodies, the more dorsal cells of this portion of pars principalis grade over into the cells of the posterior part of the lateral nucleus of the thalamus. In this region of continuity the cells are small and spindle-shaped or round, or are of mediumsize and triangular or polygonal in shape. More rostrally, the cells located ventrally within the main mass of pars principalis are not sharply delimited from those of the ventral nucleus of the dorsal thalamus. Gurdjian ('27) describes a similar continuity of these nuclei in the rat.

Along the lateral border of pars principalis the cells which constitute the pars lateralis are more flattened and more closely arranged than they are in the chief 
or central mass. The lateral portion is very thin in the mouse and is not obscrved in the most caudal sections or in the rostral fourth of the medial geniculate nucleus. This part is the portion superficielle of Ramón y Cajal ('09).

The third or ventral portion of pars principalis consists of spindle-shaped cells which are smaller and more ventrally located than those of the other two parts of the ventral group. The cells are arranged in a crescentic mass which is joined to the chief mass of pars principalis caudally. This ventral portion corresponds to area "c" of Winkler and Potter, and to noyau sus-pedunculaire of Ramón y Cajal. In mouse brain no. 87120 , it extends from $75 \mu$ anterior to the posterior pole of the medial geniculate nucleus to the rostral termination of this nucleus. It lies dorsal to the cerebral peduncle for most of its extent, and ventral to the main mass of pars principalis. Rostrally it is lateral to zona incerta at first, but then becomes continuous with the latter medially and with the reticular nucleus anteriorly. Le Gros Clark ('30) has described a similar termination for this group of cells in insectivores.

In the mice studied, pars magnocellularis begins in the most caudal fifth of the medial geniculate nucleus. It ends rostrally, along with pars principalis, by merging with the cells of the ventral nucleus of the dorsal thalamus in sections through the anterior half of the posterior commissure. Pars magnocellularis is composed of large, polygonal cells among which are found small, spindle-shaped or round cells. It has no subdivisions. Caudally it lies medial to pars principalis (fig. 9), but rostrally it is located dorsomedial to the latter portion of the medial geniculate nucleus.

Auditory cortex. The three primitive fissures found in all mammalian brains are present in the mouse. These are the hippocampal, the rhinal, and the endorhinal fissures. The endorhinal fissure is not prominent macroscopically, but, under the microscope, the infolding of the cortical laminae and the presence of the olfactory tract within the shallow groove thus created are evident. The mouse brain possesses no fissures in the neopal- lium and, because of their absence, the cortical areas are distinguished from one another chiefly on a cytoarchitectural basis. Both Drooglever Fortuyn ('14) and Maxmillan Rose ('29) have given excellent descriptions of the cytoarchitecture of the mouse brain; the works of both authors were used as references in the study of the animals reported here.

The area ascribed to audition is subdivided into two parts, the primary and the secondary auditory areas, or $T_{1}$ and $T_{2}$ (Rose, '29). At the present time this subdivision in the mouse does not depend upon functional but rests wholly upon histological differences. $T_{1}$ is bounded by the postcentral area anteriorly, the secondary auditory area inferiorly, the occipital area posteriorly, and the parietal region superiorly. It extends farther caudalward than does the secondary auditory area. $T_{2}$ lies in relation to the postcentral area anteriorly, the posterior insular area and the ectorhinal area inferiorly, the occipital area posteriorly, and the primary auditory area superiorly. It extends farther rostralward than does $T_{1}$.

A six-layered plan of organization, with modifications, exists in the mouse auditory areas, as it does in all other neocortex. According to the nomenclature used by Brodmann ('09), these layers are, in lateromedial order: Layer I, lamina zonalis; Layer II, lamina granularis externa; Layer III, lamina pyramidalis; Layer IV, lamina granularis interna; Layer $V$, Iamina ganglionaris; and Layer VI, lamina multiformis.

In the primary auditory area (figs. 11, 13), lamina zonalis is narrow and contains very few cells; these cells are fusiform in type. The second layer is not distinct, but is masked by the mediumsized pyramidal cells of the third layer. Rose ('29), for example, spoke of Layer II + III. The fourth layer is rather broad and contains numerous granular cells grouped together into clusters or knobs. These clusters are a characteristic feature of the primary auditory area and serve to distinguish it from surrounding areas in which such an arrangement of the granular cells of Layer IV is not found. Its highly developed lamina granularis interna suggests further that this area cor- 
responds to the auditory koniocortex of higher forms. Layer $\mathrm{V}$ is of medium breadth and is divided into lateral, middle, and medial strata. The lateral and medial strata possess small pyramidal cells that are widely scattered; however, rather closely arranged large pyramidal cells are found in the middle stratum. The sixth layer consists of polymorphous cells which are more densely arranged directly beneath the fifth layer than they are in the deeper part of the layer.

The primary auditory area differs from surrounding areas chiefly in the characteristic arrangement of the internal granular layer (figs. 11, 13). It may be distinguished also from the parietal area by the larger size of the pyramidal cells found in Layer $\mathrm{V}$ of the latter area; from the postcentral area with its broader Layers III and V; from the occipital area where a broader Layer I, narrower Layer IV, and lack of stratification in Layer $\mathrm{V}$ are observed; and from the secondary auditory area in which both Layers $\mathrm{I}$ and $\mathrm{V}$ are broader.

The secondary auditory area possesses a Layer I of about medium breadth. Layer II is again masked by the medium-sized pyramidal cells of Layer III. The fourth layer exhibits no clustering of its granular cells. Layer $\mathrm{V}$ is very broad and is divided into lateral, middle, and medial strata. The middle stratum is broad and is composed of large pyramidal cells; the lateral and middle strata possess small pyramidal cells. The sixth layer is narrower than in the primary auditory area and its polymorphous cells are more closely grouped in its more superficial portion.

The secondary auditory area is distinguished from the postcentral, the occipital, and the primary auditory areas by its rather broader Layer I and its very wide Layer V. It differs from the postcentral area also in possessing a narrower Layer IV than does the latter. The secondary auditory area is easily distinguished from the areas located ventral (or inferior) to it. Inferior to it, anteriorly, lies the posterior insular area in which a very wide Layer I and narrow Layers II and III are found, and in which Layer IV is not evident. Inferior to the secondary auditory area, posteriorly, lies the ectorhinal area which possesses a broad Layer I and in which Layers II, III, and IV are indistinctly separated from each other.

\section{Résumé of acoustic pathways in normal mice}

The first neurons in the acoustic pathway are bipolar cells, the cell bodies of which are located in the spiral ganglia within the cochlea. The dendrites of these cells extend peripheralward to terminate on the hair cells of the organ of Corti. Their axons accumulate on leaving the spiral ganglia to form the cochlear division of the eighth cranial nerve. The cochlear division comes into relation with the vestibular part of the acoustic nerve on its course centralward, but enters the medulla oblongata posterior to the latter and ventromedial to the ventral cochlear nucleus. Each fiber of the cochlear nerve divides immediately into a ventral and a dorsal descending branch (v. Kölliker, 1896; Held, 1893; Ramón y Cajal, '09; and others). The destination of the ventral ascending branch is the ventral cochlear nucleus, and the dorsal, descending branch terminates in the acoustic tubercle and in the dorsal extension of the ventral cochlear nucleus.

The axons of the secondary acoustic neurons on leaving the dorsal and the ventral cochlear nuclei ascend by several routes to higher centers. A bundle of fibers emerges dorsomedially from the fourth layer of the acoustic tubercle as the secondary dorsal cochlear fibers. These fibers swing dorsalward over the restiform body, then medialward through the region of the vestibular nuclei, becoming separated into smaller fascicles during their course. Many of the fibers cross the midline in the region ventral to the medial longitudinal fasciculus, forming the dorsal acoustic decussation, before turning ventralward to reach the region dorsolateral to the superior olive. Here they join secondary acoustic fibers from the ventral cochlear nucleus to form the lateral lemniscus. The number of secondary dorsal cochlear fibers remaining on the same side could not be determined in these mice.

From the ventral cochlear nucleus, secondary acoustic fibers course ventromedialward as the fibers of the trapezoid body. 
These fibers pass below or around the superior olive, through the region of the medial lemniscus, cross the midline in the ventral acoustic or trapezoid decussation, and enter the contralateral lateral lemniscus. The trapezoid decussation is much heavier than the dorsal decussation in the mouse. The more dorsal fibers of the trapezoid body are spread apart lateral to the medial lemnisci by the nuclei of the corpus trapezoideus. Numerous fibers ramify within these nuclei. In higher forms it is generally conceded that some of the secondary neurons from the ventral cochlear nucleus synapse in the trapezoid and olivary nuclei, and that contributions from these nuclei join the lateral lemnisci to ascend to higher auditory centers.

Between the dorsal and the ventral acoustic decussations is the decussation of Held. The fibers crossing the midline here appear, in the available material, to originate in the dorsal portion of the ventral cochlear nucleus as described by Ramón y Cajal ('09) and Yoshida ('24). These fibers run dorsalward over the restiform body and then dip ventralward immediately to gain a position between the dorsal secondary acoustic fibers and the trapezoid body. The fibers of Held are not numerous in the mouse.

The lateral lemniscus is composed, then, of secondary cochlear fibers from the ventral cochlear nucleus of the opposite side and from the acoustic tubercle of the same and of the opposite side. It also carries fibers from the trapezoid and olivary nuclei. In this manner, both ears are represented in each lateral lemniscus.

At lower midbrain levels the lateral lemniscus swings dorsolateralward (fig. 7). Both superior and inferior nuclei of the lateral lemniscus are present and probably receive collaterals from, and add fibers to, the lateral lemniscus. In the mouse, many of the fibers of the lateral lemniscus enter the inferior colliculus. Fibers leave the inferior colliculus laterally, turning ventralward in the capsular region. They join the portion of the lateral lemniscus which does not enter the collicular gray; together these fascicles constitute the peduncle of the inferior colliculus, which enters the medial geniculate nucleus caudomedially. Thus, fibers project to the medial genicu- late nucleus directly through the lateral lemniscus, or indirectly, after synapsing in the nucleus of the inferior colliculus.

The geniculocortical fibers gather medial to the anterior part of the medial geniculate nucleus. They assume a more lateral position as all of the cells of pars principalis except those situated most ventromedially disappear near the rostral tip of the nucleus. These fibers form the auditory radiations which run to the cerebral cortex along with the dorsal thalamic radiation. The course of the auditory radiations in the mouse corresponds to that previously described in the rat by Gurdjian ('27) and in many other mammals by various observers. There are thought to be corticocollicular as well as afferent fibers with respect to the auditory cortex in the auditory radiations.

\section{DESCRIPTION OF MATERIAL FROM DEAF MICE \\ Primary auditory centers}

Dorsal cochlear nucleus. The acoustic tubercle begins caudally at the level of the lateral recesses of the fourth ventricle. It diminishes to a narrow band of cells over the dorsal surface of the ventral cochlear nucleus in the plane of the facial roots; these cells are present to the rostral termination of the ventral cochlear nucleus. The caudorostral extent of the acoustic tubercle in the deafened animals corresponds, then, to that in the normal mice. The dorsal cochlear nucleus is not diminished in length or in breadth in the deaf mice, but is considerably flattened at all levels (figs. 4, 5,6). Along with the flattening of the nucleus there is a loss of internal organization of the nucleus which is more complete on the right side of both specimens, but which is more extensive in mouse no. 85836 than in mouse no. 85842 .

The medium-sized ovoid cells and the smaller spindle-shaped cells conspicuous in the posterior part of the acoustic tubercle in the normal mouse brain are not present in mouse no. 85836. Instead, numerous small, darkly-staining, round nuclei of cells which resemble "grains" or "granules" are prominent in this nucleus as well as in all of the higher centers for hearing in this abnormal brain. The pres- 
ence of many of these granule-type cells, then, is a characteristic feature of the changes occurring in the auditory centers of the old, deaf, epileptic waltzing mice. Similar cells may be demonstrated in the normal mouse brain, but they are more scattered and appear to be less numerous than in the abnormal material. Where they occur, these cells will be referred to as "granule-type" cells in the rest of the description given here. They may be phagocytic microglia which have invaded the various auditory nuclei; but, since special staining techniques for demonstrating neuroglia were not used, this cannot be stated with certainty.

In sections at the level of the facial nucleus in this deaf mouse there is an indication of lamination of the tubercle. The superficial layer is composed of few cells, as is the case normally. The typical fusiform cells of the second layer, lamina cellularis, are not observed here or at any other level in the nucleus; instead, the cells are large, ovoid, and pale-staining. This layer is differentiated from the other laminae because its numerous granuletype cells give it a very dark appearance. Layers III and IV in mouse no. 85836 consist of large, pale-staining cells, also, and there is a proliferation of granule-type cells especially medially. Thus, these layers cannot be distinguished from one another. The region of nucleus proprius is filled with the small granule-type cells.

There are no fibers in the caudal fourth of the acoustic tubercle or at any level in nucleus proprius in mouse brain no. 85842 . Delicate fibrils appear in the ventromedial part of the acoustic tubercle in the second fourth of its extent and gradually become more numerous. The fibers are most numerous in the anterior half of the nucleus and here, also, lamination becomes evident. The layers are thin and the fibrils in the second and third laminae are few in number and very close to one another. Layer IV is composed of small fascicles which are entering the acoustic tubercle ventrally, and of others which are leaving the nucleus dorsally.

Ventral cochlear nucleus. The ventral cochlear nucleus extends from the level of the facial nucleus caudally to that of the motor trigeminal nucleus rostrally in mouse no. 85836. It is divisible into anterior and posterior parts as in the normal animal.

The cells of the ventral cochlear nucleus are closely grouped and usually pale-staining in cell material, although occasionally they assume a characteristic violet color in Nissl preparations. They are ovoid or round rather than triangular in shape and the central parts of the cell processes are ghost-like. At the level of the vestibular division of the acoustic nerve, some of the cells in the medial portion of the ventral cochlear nucleus are triangular-shaped and have well-stained Nissl granules. These cells are closely grouped, however, and numerous granule-type cells are scattered between them. They can be traced for only $30 \mu$.

At no level does the ventral cochlear nucleus assume the shape or attain the size typical of the normal mouse brain. The most caudal part of the nucleus is much more nearly flat and narrower than in the normal material (fig. 5). It is extremely difficult to locate the cochlear nerve fibers in mouse brain no. 85836. At the level of the entrance of the vestibular nerve the ventral cochlear nucleus has a triangular shape; the base of the triangle is medialward and its apex points lateralward (fig. 6). The dorsal side of the triangle is concave; the ventral side is straight at first, but within $100 \mu$ also shows a concave curvature and becomes very short. The rostral one-half of the ventral chochlear nucleus consists of a flat layer of closely arranged cells; its dorsolateral surface is long and concave. The nucleus diminishes in size very gradually to its rostral termination. Far anteriorly the granule-type cells are numerous ventrally and along the dorsal surface of the nucleus.

In mouse brain no. 85842 the ventral cochlear nucleus also exhibits its greatest size in sections immediately anterior to the level of the cochlear nerve. It differs from this nucleus in mouse no. 85836 in that it is more rounded and not nearly so triangular in shape at these levels (fig. 4). Caudally, there are no fibers in the ventral part of the nucleus. Cochlear nerve fibers, very few in number, enter the medulla oblongata lateral to the spinal tract of $\mathrm{V}$ 
and divide into ascending and descending branches. Some of the descending branches cross the ventral cochlear nucleus, dividing it into several laminae, to enter the dorsal extension of the nucleus. The ascending branches are most numerous in the ventrorostral part of the nucleus. The ventral cochlear nucleus, except in sections at, and immediately in front of, the entrance of the cochlear nerve, is extremely flat.

Nuclear complex of the superior olive. The cells of the superior olive in mouse brain no. 85836 are of medium-size and are polygonal or fusiform in shape. They are very close together and granule-type cells are numerous among them (fig. 5). The cells appear to follow the curves or foldings of the nucleus, but aside from this arrangement no folding, such as characterizes the normal superior olive, could be demonstrated. The superior olivary nucleus is atrophied at all levels in mouse brain no. 85836 . In mouse no. 85842 it is smaller than normal but appears as a folded mass of gray which contains fibers throughout its entire extent (fig. 4).

The accessory superior olive also consists of medium-sized fusiform or polygonal cells which are closely grouped together. There is an increase in the number of granule-type cells in this nucleus in mouse no. 85836. In both specimens the accessory superior olive is more typical in size anteriorly than posteriorly.

The parolivary nuclei are difficult to demonstrate in these preparations. There is a little gray between the fibers of the trapezoid body ventral and ventrolateral to the superior olive in mouse brain no. 85842. In mouse no. 85836 a few polygonal cells are found in these nuclei.

The nuclei of the trapezoid body are well developed in both mice. The cells of the trapezoid gray are of medium-size and polygonal or ovoid in shape. They are closely arranged in mouse no. 85836 and there is a proliferation of granule-type cells in the nucleus. In mouse no. 85842 , although there are fewer fascicles separating the gray of the nucleus, many fibers leave it medially, and there is a heavy trapezoid decussation in the region between the gray of the two sides.
Nuclei of the lateral lemniscus. The inferior nucleus of the lateral lemniscus is composed of closely arranged, polygonal or fusiform cells of medium-size. Here, again, granule-type cells appear to be more numerous than in the normal material. Anteriorly, the inferior nucleus is connected to the superior nucleus of the lateral lemniscus by strands of cells which are part of the latter nucleus (fig. 8). These strands are widely separated in mouse brain no. 85836 , indicating the passage of many fibers; in mouse no. 85842 there are marked fiber connections between these nuclei.

The dorsal portion of the superior nucleus of the lateral lemniscus consists of fusiform cells which are arranged with their long axes in a horizontal plane. The cells are closer to one another than they are in normal material. In mouse no. 85842, very few fibers enter the nucleus of the inferior colliculus from the superior nucleus of the lateral lemniscus.

Inferior colliculus. The inferior coliculus is divided into a central nucleus and a peripheral capsular portion, as is the case in the normal animal. The central nucleus is a dense, cellular area; the large polygonal cells characteristic of this nucleus are present, but between them and in the capsular portion are numerous granule-type cells. The dark, round nuclei of these cells are conspicuous and give a granular appearance to the inferior colliculi (fig. 8). In mouse no. 85842 there are many fine fibers in the central nucleus, but few fibers enter the peduncle of the inferior colliculus.

Medial geniculate nucleus. The medial geniculate nucleus begins caudally at the level of the superior colliculus and terminates rostrally in sections through the middle third of the posterior commissure. Anteriorly, the cells of this nucleus are confluent with the cells of the ventral nucleus of the thalamus. In these respects, then, the deaf mice do not differ from the normal animals. They do differ from them in that the medial geniculate nucleus is atrophied in the deaf mice, especially lateromedially and dorsally, and there is a lack of the typical internal organization. Most caudally the medial geniculate nucleus of mouse brain no. 85836 is a small 
mass of compactly arranged cells. Some of these cells are ovoid, medium-sized neurons; others are granule-type cells. As the nucleus increases in size, pars principalis and pars magnocellularis are distinguishable.

Pars principalis is laterally situated and is composed of pale, ovoid cells of mediumsize, and of many prominent granule-type cells (fig. 10). The nuclear membranes of the ovoid cells are well-stained and clearly visible, but neither the cytoplasm nor the karyoplasm stain well. Frequently the cell processes are pale or do not stain at all. The dark, triangular or spindleshaped cells of the dorsal group are not present; granule-type and ovoid cells are found in this part of pars principalis. Laterally, the cells are ovoid, also, and are much more closely arranged than in the normal material. The central mass of pars principalis is atrophied in its entire caudorostral extent. The ventral part of this nuclear mass, which is less atrophied than the more dorsal portion, contains some scattered triangular or fusiform cells. The most ventral cell group of pars principalis is filled with granule-type cells, although a few pale, ovoid cells can be distinguished.

Pars magnocellularis of the medial geniculate nucleus is poorly defined caudally. Its cells are close to one another and numerous granule-type cells are present here as well as in the area between this nucleus and pars principalis. In its rostral third the large, polygonal cells typical of this area in the normal mouse brain are occasionally evident.

The degeneration is very similar in the medial geniculate nuclei of mouse brain no. 85842 and mouse brain no. 85836 . The caudal fourth of pars principalis in mouse brain no. 85842 is devoid of fibers exccpt most ventrally. Fibers are present in the anterior three-fourths of this nucleus and, in this better preserved portion, they are most numerous centrally. A few fibers ramify laterally and dorsally in pars principalis at the level of the caudal pole of the dorsal part of the lateral geniculate nucleus. Rostral to this level, pars principalis is an oval-shaped gray mass in which there are few fibers. The small pars magnocellularis is never rich in fibers.
Auditory cortex. The histological structure of the auditory cortex is not well differentiated in mouse brain no. 85836 except in a few areas. The most prominent feature of the degeneration in the auditory cortex of this animal is the similarity of the cells in Layers II, III, and IV; these cells are ovoid in shape and possess pale-staining nuclei and cytoplasm (fig. 12). The proportion of granule-type cells appears to be increased in the auditory areas of the deaf mice, but these cells are not nearly so conspicuous here as they are in the primary acoustic nuclei.

Layer I of the primary auditory area in mouse brain no. 85836 is relatively unaffected. Layers II and III are confluent and consist of the inflated, ovoid cells described above. There are a very few dark, small pyramidal cells in the medial part of Layer III on the right side. These are located in the most superior and rostral portion of the primary auditory area and are not observed elsewhere. There is a clustering of the granular cells in Layer IV superiorly in the rostral third of the auditory koniocortex; this clustering is bilateral. Immediately ventral to the clusters, Layer IV thins out and the cells are not arranged in knobs, as in typical auditory cortex. Layers II + III and IV are confluent here as well as in the entire caudal two-thirds of the primary auditory area. Layer $\mathrm{V}$ is also best differentiated rostrally. Its three strata are distinct, although the large pyramidal cells of the middle stratum are slightly enlarged and take a pale stain. This stratification is not observed caudally. Layer VI is composed of polymorphous cells which do not appear to differ in arrangement at different depths.

Layer I of the secondary auditory area is not affected in this mouse brain. Layers II, III, and IV are indistinct, all of them being composed of pale, ovoid cells. Layer $\mathrm{V}$ is very broad, and its pyramidal cells are large and "ghost-like." Layer VI is not differentiated into superficial and deep strata. On the left side Layers II, III, IV and V are confluent, indicating that degeneration is more complete, and perhaps has occurred earlier on this side.

Unfortunately, a few of the sections of the auditory cortex are missing from the 
left side in mouse no. 85842; these were lost in preparation of the material. In the rest of the sections fibers reach the auditory areas and, in some cases, radiate into Layer IV. The primary auditory area exhibits a knob-like arrangement of Layer IV rostrally on both sides. This is best seen superiorly on the right and inferiorly on the left. There are clusters of neurons in the fourth layer throughout approximately the caudal third of the right koniocortex. Delicate fibers can be traced through Layer IV in this region.

The secondary auditory area is better supplied with fibers on the right side than on the left. The fibers enter Layer II + III toward the middle of the area. On the left side fibers are found only in Layer VI and in the medial part of Layer $\mathrm{V}$.

\section{Acoustic pathway in deaf mice}

None of the parts of the acoustic pathway are completely degenerated in these deaf mice, except the roots of the cochlear nerve on both sides in mouse brain no. 85836. The fibers in other portions of the auditory pathway are greatly diminished in number.

The cochlear nerve is much reduced in size even in mouse no. 85842. It appears to be about one-third the size of the nerve in the normal mouse. Upon entering the medulla oblongata, each fiber bifurcates into two branches: the descending branch runs in a dorsal direction through or medial to the ventral cochlear nucleus to end in the dorsal extension of this nucleus and in the acoustic tubercle; the ascending branch terminates in the ventral cochlear nucleus. This bifurcation of the acoustic nerve is well defined in sections cut at an angle. Within the primary acoustic nuclei the regions containing most fibers are those close to the entrance of the cochlear nerve. The acoustic tubercles are almost completely degenerated in mouse no. 85836 , but only the caudal fourth of these nuclei entirely lack fibers in mouse no. 85842. Nucleus proprius in the latter mouse brain is atypical throughout its extent. The ventral cochlear nucleus is largest and best supplied with fibers at the level of, and just anterior to, the entrance of the cochlear nerve (fig. 4). At similar levels in mouse brain no. 85836 the ven- tral cochlear nucleus is smaller than normal and triangular in shape.

A few fascicles swing dorsalward from the acoustic tubercles of mouse no. 85842; they turn ventromedialward to cross the midline in the dorsal acoustic decussation. There are also a few fibers of Held which arise in the dorsal extension of the ventral cochlear nucleus in this material, run dorsalward over the restiform body, and then dip ventralward (fig. 4). It is impossible to determine the percentage of secondary dorsal acoustic fibers remaining on the same side. The secondary acoustic neurons from the acoustic tubercle and the dorsal extension of the ventral cochlear nucleus enter the lateral lemniscus, lateral to the superior olive, where they are joined by other fibers from the contralateral ventral cochlear nucleus. The fascicles from the ventral cochlear nucleus are not so numerous as in the normal brain. They leave the nucleus ventromedially and may send collaterals into the nuclear complex of the superior olive and into the trapezoid gray. In spite of the fact that fewer fibers of secondary neurons leave the ventral cochlear nuclei in both abnormal brains, there is a well developed trapezoid body medial to the trapezoid gray, and a heavy ventral acoustic decussation.

\section{RÉSUMÉ}

In general then, a high degree of organization is not to be found in the acoustic centers in the deaf mice. Instead, there is usually a lack of organization; the cells of the various nuclei are frequently inflated and "ghost-like" in appearance, and the laminae of the acoustic tubercles and of the auditory cortex are usually confluent. The fibers, when present, are delicate. The most striking change is in the appearance of the ventral cochlear nuclei, for in the deaf mice they are atrophied and they may have a triangular shape. Normally, these nuclei have a plump, rounded contour.

There is no doubt that the older, epileptic waltzers become deaf due to degenerative changes within the auditory centers and pathway. The interesting aspect of this degeneration is that the entire system is involved, rather than one particular 
portion of it. There is some evidence that the degeneration affects particularly the primary acoustic nuclei, however, for these nuclei are almost completely atrophied in the deaf mice, while a few typical appearing cells and cell groupings are observed at higher levels. Although the right primary acoustic nuclei are more atrophied than the left, the higher centers are more severely affected on the left side. All of these factors indicate either a gradual, simultaneous degeneration of the various auditory centers corresponding with the gradual loss of hearing exhibited by the animals, or else a transneuronal type of degeneration.

In order to determine more exactly the nature and course of the degeneration, it is necessary to examine the auditory pathways of partially deaf epileptic waltzers. This will be done in Part II of this study.

\section{LITERATURE CITED}

Brodmann, K. 1909 Vergleichende Lokalisationslehre der Grosshimrinde in ihren Prinzipien dargestellt auf Grund des Zellenbaues. J. A. Barth, Leipzig, 334 pp.

Crosby, E. C., and J. W. Henderson 1948 The mammalian midbrain and isthmus regions. II. Fiber connections of the superior colliculus. B. Pathways concerned in automatic eye movements. J. Comp. Neur., 88: 53-92.

Dice, L. R. 1935 Inheritance of waltzing and of epilepsy in mice of the genus Peromyscus. J. Mammalogy, 16: 25-35.

Fortuyn, A. B. Droogleever 1914 Cortical cell lamination of the hemispheres of some rodents. Arch. Neurol. Psychiat., 6: 221-354.

Guild, S. R. 1919 War deafness and its prevention - report of the labyrinths of the animals used in testing of preventive measures. (Middle ears previously reported). J. Lab. \& Cl. Med., 4: 1-28.

Gurdjian, E. S. 1927 The diencephalon of the albino rat. Studies on the brain of the rat. No. 2, J. Comp. Neur., 43: 1-114.
Held, H. 1893 Die centrale Gehorleitung. Arch. f. Anat. u. Entwickl. (Leipzig), pp. 201-248.

Kölliker, Von A. 1896 Handbuch der Gewebelehre des Menschen. Bd. 2, W. Engelmann, Leipzig, $874 \mathrm{pp}$.

Le Gros Clark, W. 1930 The thalamus of Tarsius. J. Anat. (Lond.), 64: 371-414.

- 1933 The medial geniculate body and the ganglion isthmi. Ibid., 67: 536-548.

Lorente de Nó, R. 1933 Anatomy of the eighth nerve. III. General plan of structure of the primary cochlear nuclei. Laryngoscope, 43: 327-350.

Malone, E. F. 1910 Ueber die Kerne des menschlichen Diencephalon. Abhandl. d. kon. preuss. Akad. d. Wissench., Berlin, Phys.-math. Cl. Abh 1, 32 pp.

Ramón y Cajal, S. 1909 Histologie du système nerveux de l'homme et des vertébrés. A. Maloine, Paris, Vol. I, $986 \mathrm{pp}$.

1911 Histologie du systeme nerveux de l'homme et des vertebres. A. Maloine, Paris, Vol. II, $993 \mathrm{pp}$.

Rioch, D. McK. 1929 Studies on the diencephalon of Carnivora. Part I. The nuclear configuration of the thalamus, eipthalamus, and hypothalamus of the dog and cat. J. Comp. Neur., 49: 1-119.

Rose, M. 1929 Cytoarchitektomischer Atlas der Grosshirnrinde der Maus. J. f. Psychol, u. Neurol, 40: 1-51.

Vogt, C. 1909 La myéloarchitecture du thalamus du cercopithèque. Ibid., 12: 285-324.

Walker, A. E, 1937 The projection of the medial geniculate body to the cerebral cortex in the macaque monkey. I. Anat. (Lond.), 71: 315-344.

- 1938 The primate thalamus. The Univ. of Chicago Press, Chicago, 321 pp.

Watson, M. L. 1939 The inheritance of epilepsy and of waltzing in Pcromyscus. Dissertation. Contributions from Lab. of Vert. Gen., 11: 1-24.

Winkler, C., and A. Potter 1911 An anatomical guide to experimental researches on the rabbit's brain. W. Versluys, Amsterdam, 40 frontal sections.

- 1914 An anatomical guide to experimental researches on the cat's brain. W. Versluys, Amsterdam, 35 frontal sections.

Yoshida, I. 1924 Ein Beitrag zur Anatomie des Octavus. Folia anat. japon., 2: 275-281. 


\section{PLATES}

\section{Abbreviations to plates}

Ac. tub., Acoustic tubercle

"chief mass," "chief mass" of pars principalis of the medial geniculate nucleus

Coch. N., Cochlear Nerve

d. gr., Dorsal group of pars principalis of the medial geniculate nucleus

Fib, from "tail" post. subd, v. coch. nuc., Fibers from the "tail" of the posterior subdivision of the ventral cochlear nucleus

Inner str., Inner stratum of Layer V of the primary auditory cortex

I. gr., Lateral group of pars principalis of the medial geniculate nucleus

L. lem., Lateral lemniscus

L. zone, Lateral zone of the ventral cochlear nucleus

L. I to L IV, Layers of the acoustic tubercle

Lam. I to VI, Laminae of the primary auditory cortex

M. zone, Medial zone of the ventral cochlear nucleus

Med. gen., Medial geniculate nucleus

Middle str., Middle stratum of Lamina V of the primary auditory cortex

Nuc. inf. col., Nucleus of the inferior colliculus

Nuc. inf. 1. lem., Inferior nucleus of the lateral lemniscus
Nuc. prop., Nucleus proprius

Outer str., Outer stratum of Lamina $V$ of the primary auditory cortex

P. magnoc., Pars magnocellularis of the medial geniculate nucleus

P. prin., Pars principalis of the medial geniculate nucleus

Post. subd. v. coch. nuc., Posterior subdivision of the ventral cochlear nucleus

Rest. body, Restiform body

Rost. subd, v, coch. nuc., Rostral subdivision of the ventral cochlear nucleus

Sp. tr. V, Spinal tract of V

Sup. nuc. l. lem., Superior nucleus of the lateral lemniscus

Sup. ol. nuc., Superior olivary nucleus

"Tail" post. subd. v. coch. nuc., "Tail" of the posterior subdivision of the ventral cochlear nucleus

Trap, body, Trapezoid body

v. gr., Ventral group of pars principalis of the medial geniculate nucleus

V. coch. nuc., Ventral cochlear nucleus

V. port. post. subd. v. coch. nuc., Ventral portion of the posterior subdivision of the ventral cochlear nucleus 
PLATE 1

EXPLANATION OF FIGURES

1 A transverse section through the caudal part of the acoustic tubercle of mouse brain no. 87120 to show the beginning of lamination within the tubercle. Cresyl-echt-violet stained preparation. $\times 60$.

2 Normal mouse brain no. 87120. The acoustic tubercle and the posterior subdivision of the ventral cochlear nucleus are shown in this transverse section. Cresyl-echt-violet stained preparation. $\times 50$.

3 The acoustic tubercle and the anterior subdivision of the ventral cochlear nucleus of the normal mouse are shown in a cross section at a level through the caudal part of the genu of VII. This photomicrograph shows the rounded contour of the ventral cochlear nucleus as the "tail" of the posterior subdivision of this nucleus disappears. Mouse brain no. 87120. Cresyl-echt-violet stained preparation. $\times 50$. 


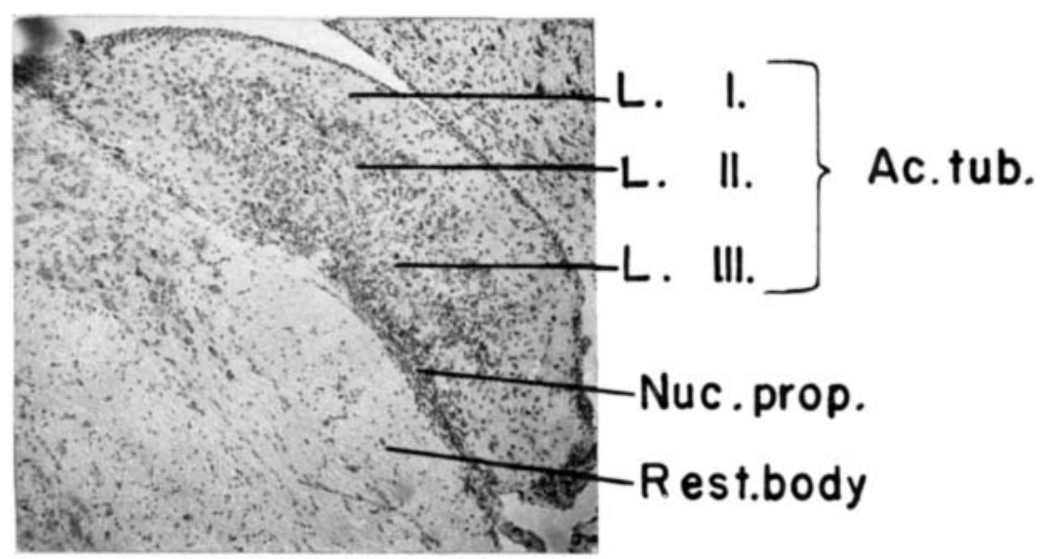

\section{FIG. I.}

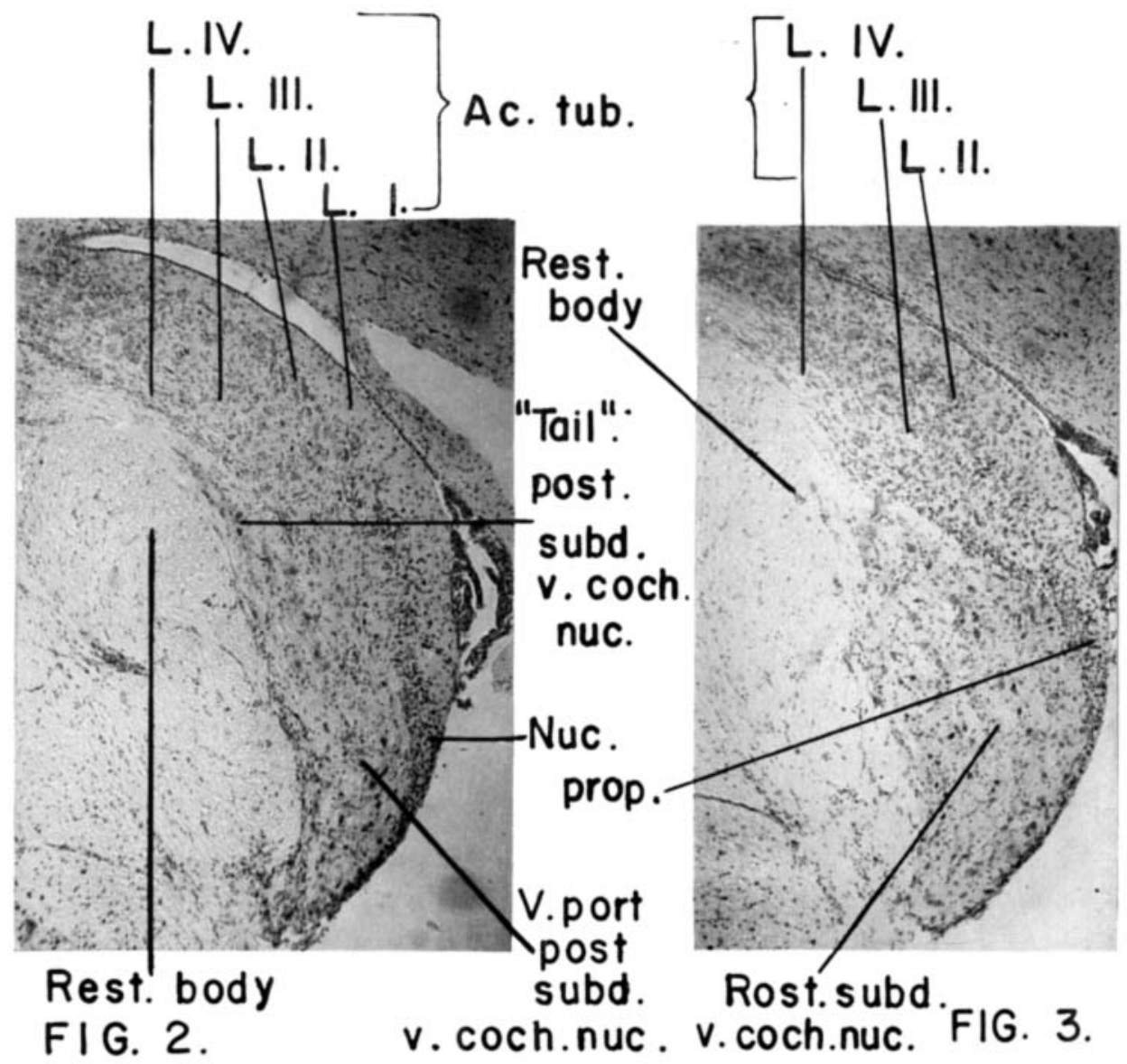


PLATE 2

EXPLANATION OF FIGURES

4 This transverse section through the dorsal and ventral cochlear nuclei of the deaf mouse, (brain no. 85842), at the level of the cochlear nerve shows a few fibers from the "tail" portion passing dorsalward. Note the general loss of fibers exhibited throughout the section. Weil stained preparation. $\times 25$.

5 Note the close arrangement of the small, dark-staining nuclei of the granule-type cells in the abnormal dorsal and ventral cochlear nuclei in this transverse section. The pronaunced lack of organization within the superior olivary nucleus also may be observed. Mouse brain no. 85836 (deaf). Cresyl-echt-violet stained preparation. $\times 25$.

6 A transverse section through the anterior subdivision of the ventral cochlear nucleus at the level of the cochlear nerve is shown here. This section is from the deaf mouse no. 85836 series, and may be compared with figures 3 and 4 to show the profound changes in internal organization and in contour which have occurred in the ventral cochlear nucleus of this brain. Cresyl-echt-violet stained preparation. $\times 45$. 


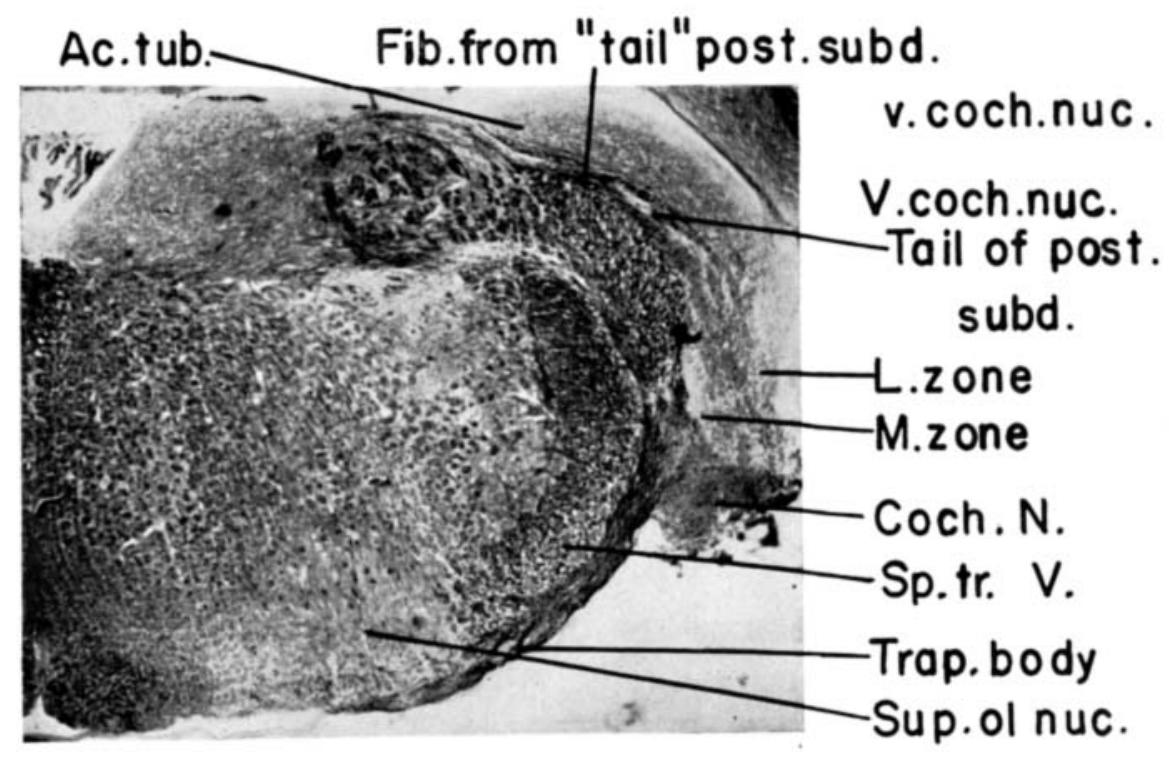

FIG. 4.

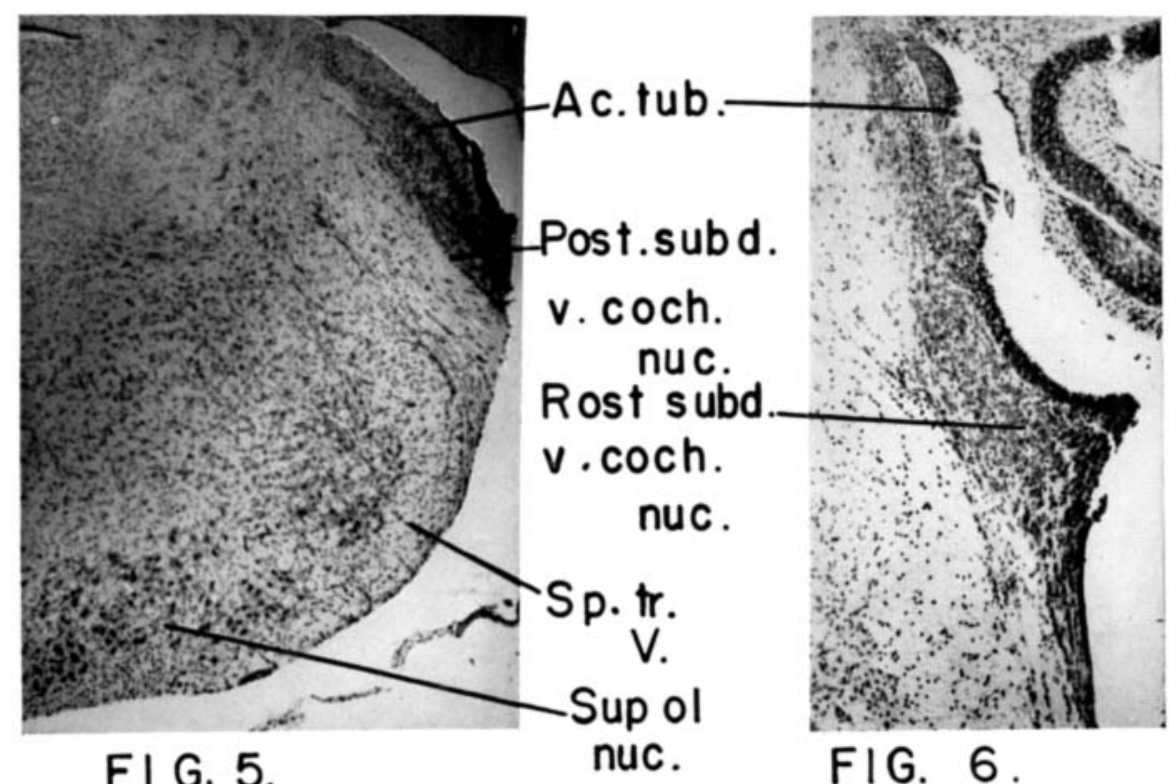


PLATE 3

\section{EXPLANATION OF FIGURES}

7 A transverse section at the level of the inferior colliculus in the normal mouse, no. 87932, Weil stained preparation. $\times 32$.

8 A transverse section at the level of the inferior colliculus in the deaf mouse, no. 85836. The granule-type of cell is very conspicuous throughout the level and a diminution in breadth of the brain is obvious. Cresyl-echt-violet stained preparation. $\times 20$.

9 The various groups of pars principalis in the normal medial geniculate nucleus are shown here. The dorsal group is especially clear. Mouse brain no. 87120. Cresyl-echt-violet stained preparation. $\times 32$.

10 This is a photomicrograph of a transverse section through the medial geniculate nucleus of the deaf mouse (no. 85836) at the same level as the section shown in figure 9. The cells of the various groups of pars principalis resemble each other closely. Typically they are swollen and pale staining, so that the groups can not be differentiated. Cresyl-echt-violet stained preparation. $\times 50$ 
Sup nuc. I.lem.

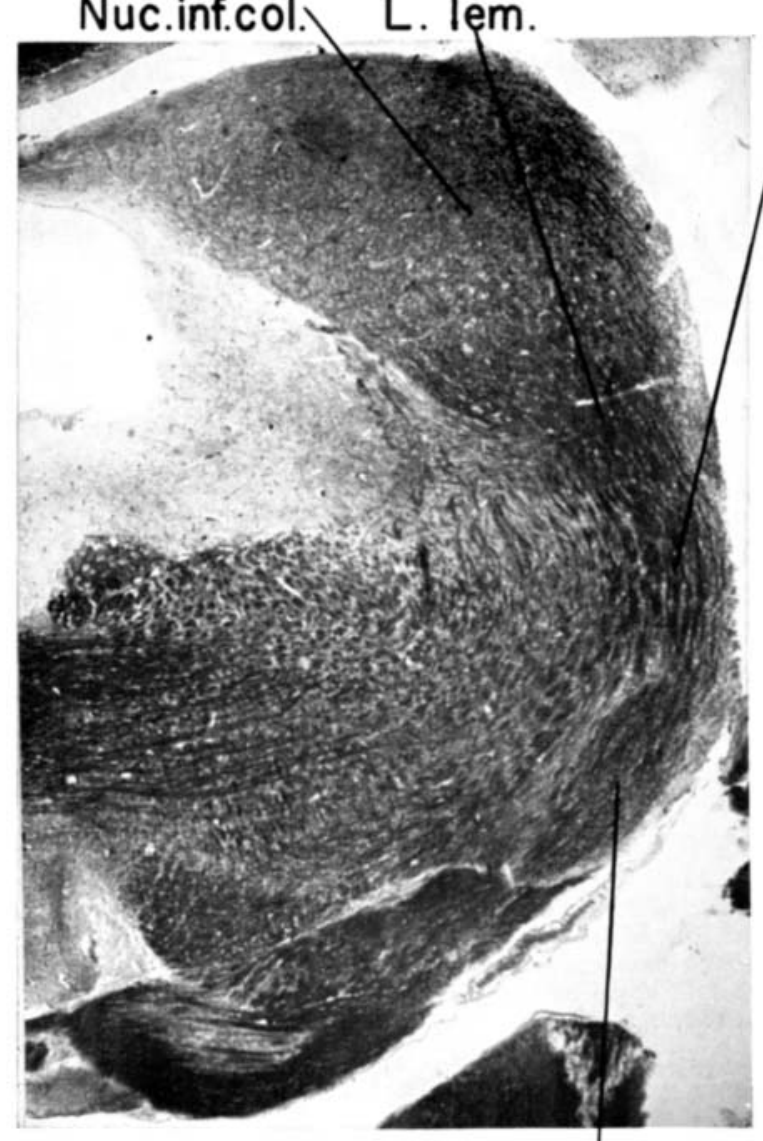

FIG. 7 .

Nuc.inf. I. lem. $\bigwedge$ Nuc. inf. col.

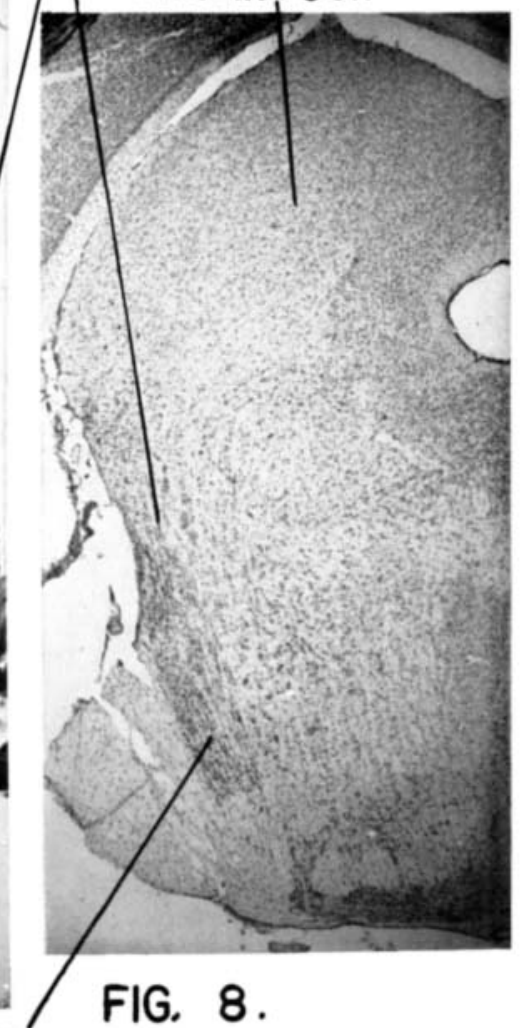

FIG. 8 .

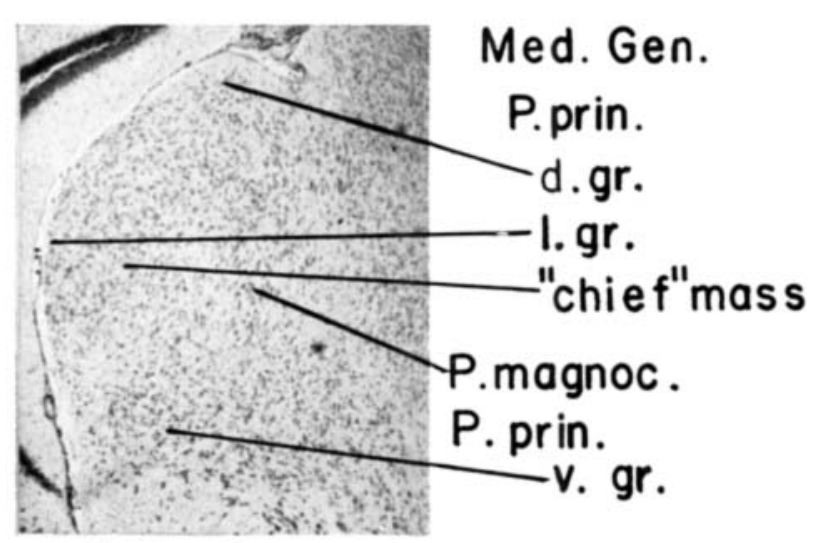

FIG. 9.

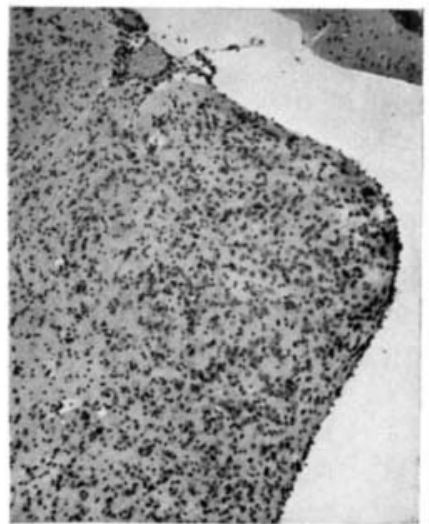

FIG. 10. 
PLATE 4

EXPLANATION OF FIGURES

11 The primary auditory cortex of the normal mouse brain may be divided into six layers as is shown in this photomicrograph. This section was taken from the middle third of the extent of the primary auditory area of mouse brain no. 87932. The clusters or "knobs" in Lamina IV are especially obvious in the Weil preparation. Weil stained preparation. $\times 65$.

12 This section shows the inflated-appearing, "ghost-like" cells which appear in Laminae II, III, IV, and V of the primary auditory cortex in the deaf mouse (brain no. 85836). The changes in size and shape of the cells as well as the loss of internal organization of the cortex may be quickly demonstrated by comparing this section with a similar level in the normal mouse brain as is given in figure 13. Cresylecht-violet stained preparation. $\times 65$.

13 A transverse section through the middle third of the auditory cortex of the normal mouse (no. 87120). The clustering of Lamina IV is evident as is the layering of the fifth Lamina. The cells of Lamina VI are divided into numerous bands or "sheets" by the fibers which course between them, Cresyl-echt-violet stained preparation. $\times 55$. 

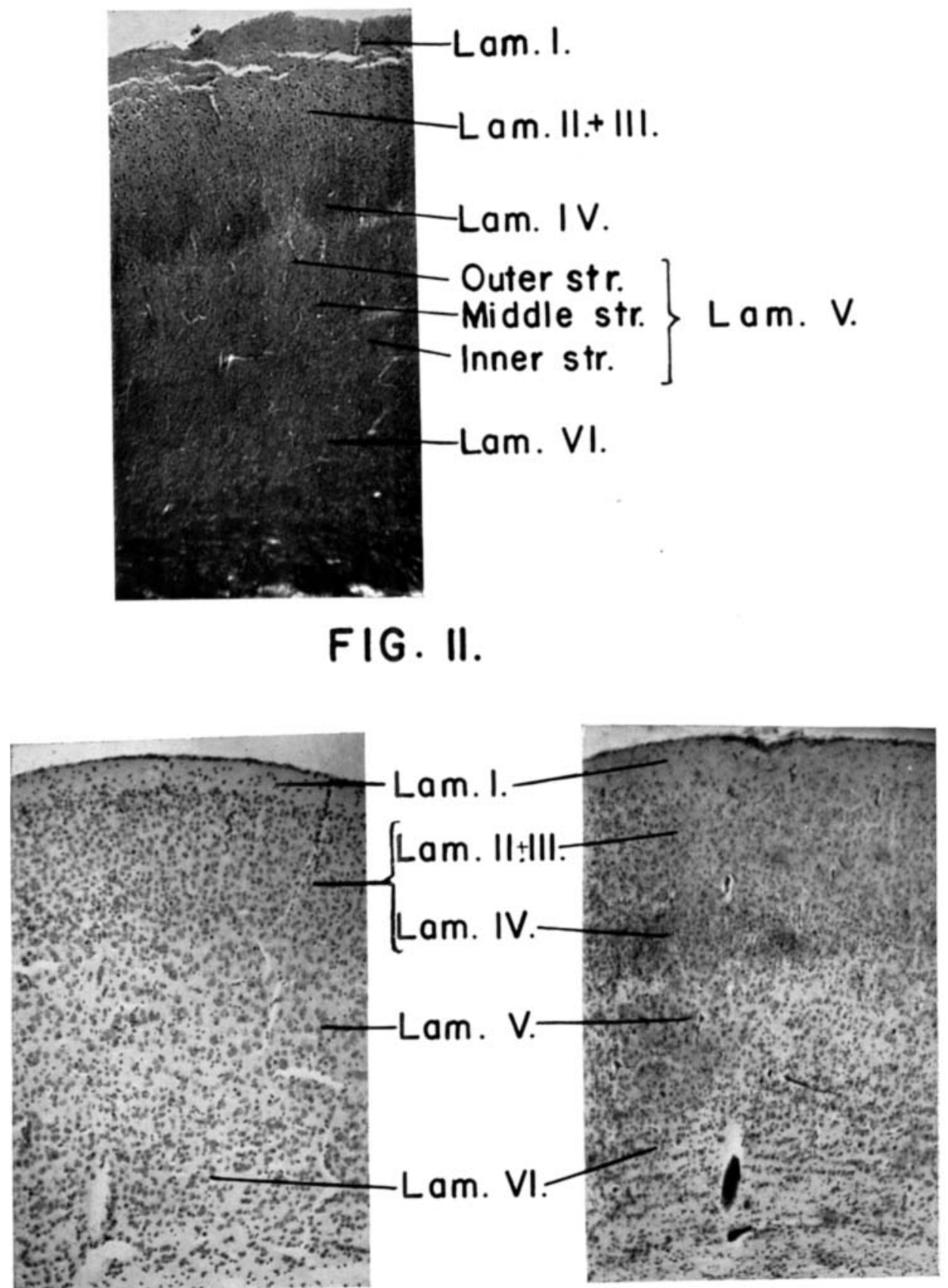

FIG. 12 .

FIG. 13. 